\title{
OECD Employment Protection Legislation Indicators and reform
}

Ewan McGaughey ${ }^{1}$

The following remarks were given at a workshop on 27 June 2019 at the Organisation for Economic Cooperation and Development. Minor additions, reflecting other points raised in the discussion, have been made.

Thank you for having me here at the OECD, I am delighted to have been invited. My name is Ewan McGaughey, and I work as a senior lecturer at the law school of King's College, London. The three main issues that I would like to talk about concern (1) the conceptual framework, including the methodology, of the OECD EPL Indicators, (2) the substance and coding of the indicators, including significant problems that we can see, and (3) the practical implications which flow from the Indicators as they currently stand.

It may also be worth saying something briefly about where I am coming from. As I say, I work as a senior lecturer at King's College, London, and am also a research associate at the Centre for Business Research at the University of Cambridge. The CBR, as many of you know, has developed a new set of indicators, encompassing 40 types of labour rights, in 117 countries, with changes going back to 1970, led by Simon Deakin, Zoe Adams and Louise Bishop. Like the International Labour Organisation's EPLex indicators, there are significant differences between the CBR Labour Regulation Index, and the OECD's. Part of the reason I became involved with the CBR has been my work on both law and economics. I undertook my $\mathrm{PhD}$ at the London School of Economics, where we were strongly encouraged to engage in interdisciplinary work. All too often I hear lawyers disparaging the economics profession for lack of legal understanding, while it is common to hear economists criticising lawyers for lacking an understanding of economic issues. The truth is, the best work comes from combining all fields of knowledge in social sciences and humanities, whether that is law, economics, sociology, history or politics, just like the great lawyer, and chair of moral philosophy in Glasgow - Adam Smith - was also the father of economics. I will not go into Plato or Weber (also lawyers) and their contributions to philosophy and sociology. Fundamentally, we ought to be bringing a combined, interdisciplinary understanding to all modern research. This is why it is especially important to scrutinise the OECD EPL Indicators from multiple perspectives.

1 Senior Lecturer, School of Law, King's College, London. Research Associate, Centre for Business Research, University of Cambridge. Please contact at ewan.mcgaughey@kcl.ac.uk or @ewanmcg with any comments. 


\section{Conceptual framework}

So, first: the conceptual framework of the EPL Indicators. As has been pointed out, the OECD states that the:

'EPL indicators quantify the costs and procedures involved in dismissing individuals.'

Implicitly, dismissal protection is framed with considerable, if not decisive, emphasis on the 'costs' to employers. This is highly problematic. It does not recognise the considerable benefits to employers (to say nothing about benefits to employees or aggregate social welfare) of dismissal protection itself. This is because of the omnipresent spectre of conflicts of interest that management organs within a firm have. These conflicts mean that dismissal protection may benefit rational employers in the long-run, despite superficial 'costs' to irrational, short-termist managers. Three main categories can be identified: personal, stakeholder, and social conflicts.

First, there are personal conflicts of interest. Suppose that a bad manager dismisses a good worker because of irrational conflicts of personality. The employer, or the firm as a whole, has a strong interest in ensuring that there are fair procedures, which simply may not be possible without having recourse to external adjudication. Without such accountability there is a reduced incentive for the firm to engage in efficient management practice. Therefore, good employers should want to ensure there is dismissal protection in their own financial interest.

Second, there are stakeholder conflicts of interest. Suppose that shareholders wish to make employees redundant in order to prop up the level of dividends that they receive, or that directors wish to reduce the 'wage bill' to inflate their bonuses, even though loss of good, longterm staff will damage the trust and confidence, and long-term success of the enterprise. If the law ensures that the social costs of redundancies are fully internalised by the firm, these incentives to arbitrarily redistribute wealth from employees to shareholders and directors are at least limited. It follows that a rational firm - and a long-term investor or an enlightened management - interested in its own long-term prosperity (not short-term profiteering) should see employment protection, not as some 'cost', but as a benefit.

Third, there are social conflicts of interest. As we know, in a depression, firms acting in their own individual, rational interest, may begin dismissing staff, predicting a future downturn of business. But if every firm does the same, this results in fewer workers employed across the economy, having less in total income to spend on business goods and services. This results in lower aggregate demand, which leads to further business losses, and further redundancies. 
Rational private choices may result in socially irrational outcomes. This is why - as we saw in the wake of the financial crisis in Germany - many employment protection laws limit socially conflicted business decisions. Quite apart from social costs, it is also in the long-term economic interest of all firms. Worker participation in dismissal decisions, again, limits short-term irrational dismissals. The bottom line is that in their own interests employers cannot merely see employment protection legislation as a 'cost', but it is simultaneously, and inextricably, a benefit.

This is why the conceptual framing of the OECD Indicators to 'quantify the costs and procedures' in dismissal is highly problematic. This could be avoided by shifting, like the CBR Labour Regulation Index, to a conceptual frame based upon the functional protectiveness to the worker. But as it stands, the OECD frame risks looking at only one side of the 'cost' equation, and therefore having an ideologically loaded starting point.

It may also be added, that the OECD's framing of the 'strictness' of EPL presents a similar problem. This frame pays no regard to the strictness, inflexibility, or rigidity that results from unrestricted powers of contract and property in the hands of the employer, and how this may be economically damaging. It fails to recognise the serious market failures which result from the structurally inequality of bargaining power between workers and employers. Employers can 'hold out' longer because they have more resources: A Smith, The Wealth of Nations (1776) Book I, ch $8, \$ 12$. Employers are usually better organised collectively, usually in a corporate form, so that workers have greater obstacles to taking collective action: JS Mill, Principles of Political Economy (1848) Book V, ch XI, \$12. Conversely, without legal dismissal rights, competition among employers makes it hard for employers to credibly commit to job security (which could raise worker trust and productivity) because one employer can easily 'defect', make more profit, and through cut-throat competition drive a race to the bottom. Unequal bargaining power (and the resulting market failures regarding marginal productivity) is often hard to calculate because of informational uncertainty: T Piketty, Capital in the $21^{\text {st }}$ Century (2014) ch 9, 331-4. This is why a job security cannot easily be classified as 'strict' without further institutional analysis.

In addition to the conceptual framing, the methodology of the Indicators is deeply problematic. As has already been mentioned, credible references are not given for any but a few of the numbers in the central EPL Indicators. While there is a country profile for each OECD member, these do not contain anything close to verifiable legal information, by which it can be determined how the countries' laws are assessed and ranked. This is a methodological, and also a philosophical problem. If references are not given, the number ranking for any country's law 
cannot be assessed, and therefore no claim can be substantiated or falsified. The impossibility to falsify a claim is a basic conceptual problem.

\section{Substance and coding}

Second, moving to the substance and coding, although the methodology is opaque, from what can be deduced about the OECD EPL Indicators, it is clear that there are multiple errors, and multiple claims which are obviously wrong. I have not engaged with all countries, but from the systems that I know best - the UK, Germany, the US, and EU law - I can give several examples (and this is just a sample) to illustrate this point. For example,

- in the first indicator, Reg 1, for the United States it is said that 'Workers in the United States generally do not have contracts.' This is wrong on an elementary level, because all workers have contracts, they just may be oral, rather than written. More substantially, Reg 1 then goes on to give a score to the US of 0.54 out of 1 , based upon the number of states which require that an employer gives a 'service letter' to employees upon termination. My understanding (from very rudimentary research) is that 15 out of 50 states require such letters $(30 \%$ of states), while the number allocated to the US suggests $54 \%$. The issue is not whether I am right, or the OECD indicator is correct, but that nobody has any way to verify the reasoning of the OECD indicator. However, it also seems that the OECD indicator contains a significant typographical error: it states that ' $28 \%$ of the US population' is covered. It would seem that the drafter has then turned this into an indicator of 0.54 by reading its own country profile as 28 out of 50 states (i.e. $54 \%$ of states?). Given that the first indicator, in the OECD's largest member state, is riddled with errors, it is fair to conclude that the entire OECD EPL Indicator set may be exposed to similar errors, which must require swift correction.

- in the United Kingdom's indicators, Reg 11, on the maximum number of renewals for fixed term contracts, the UK is awarded 'zero' because it is thought there are no rights. This has missed the norm (of fundamental importance) that the Employment Rights Act 1996 section 95(1)(b) states that the expiry of a fixed term contract is deemed to be a dismissal, and must therefore (after the current qualifying period of 2 years) be justified like any other dismissal. This means the effective limit on fixed-term contracts is 2 years. In addition, employees have a further express statutory right to a permanent contract after 4 years: Fixed-term Employees 
(Prevention of Less Favourable Treatment) Regulations 2002 reg 8. Similar rights apply across the EU.

- comparing the indicators of Italy and Germany, the OECD awards Italy a score of '2.89' for the 'strictness' of employment protection, but only gives Germany a score of '2.84'. This is problematic because on any credible legal view, German law is much more beneficial to workers (and rational employers, as explained above) because of the strength of elected work councils in vetoing or deferring employer dismissal decisions. In Italy, there is no right of a work council to defer a dismissal decision at all.

These three examples illustrate how the OECD Indicators distort the overall picture of EPL. The OECD Indicators suggest that the US and UK are relatively close to one another in terms of job protection, and that other EU member states such as Germany and Italy are comparably high. But no credible comparative lawyer would endorse this view. The US system of dismissal protection is 'at-will employment': there are no federal or state rights to reasonable notice in individual dismissals, to a fair dismissal, to redundancy pay, or to participation in dismissal decisions. Any irrational employer can (like Donald Trump) say 'you're fired' for a good reason, a bad reason, or no reason at all. The relative weight of state duties to give a 'service letter' is minimal, and certainly would not warrant a ' 1 ' compared to (as the OECD methodology document indicates) the ' 3 ' that results with the right of a 'third party' work council (as in Germany) being able to defer a dismissal. The true picture is that EPL in the US is close to zero, the $\mathrm{UK}$ is higher and closer to other EU member states, while the strongest (and most flexible) systems are those with elected work councils, or where workers participate in dismissal decisions.

A central omission in the OECD Indicators is that they isolate 'employment protection legislation' (a phrase deriving from 1970s UK statute) from the strength of collective bargaining rights, and from information, consultation, and participation rights, particularly through work councils and representation of workers on enterprise boards. But collective bargaining is crucial for job security, as is the right of workers to participate in dismissal decisions. It is impossible to segregate different elements of labour laws from one another: very often rights are indivisible. In this way, the OECD indicators - while often being overly detailed on issues of practically minor weight - do not include enough.

The good news is that it would be relatively easy to engage a series of legal experts for each country to rewrite the OECD indicators and the numbers attributed to each country. It is likely that the results would appear very similar to those recorded in the CBR Labour Regulation 
Index or the ILO EPLex. It is worth adding that nobody would suggest that the CBR index is free from legal mistakes or omissions, but the critical fact is that everything is transparent and open to constant improvement and revision. Indeed, simply copying those indicators' material could be a useful starting point for reform. Working with other organisations cannot go wrong.

\section{Practical implications}

The errors in the substance and coding of the OECD Indicators have very significant practical implications. As has been said, they have been widely relied upon in economic literature, even though the users in most of these studies do not engage critically (if at all) with the methodological, legal and evidential defects even if they themselves are distinguished legal experts (e.g. M Roe, Political Determinants of Corporate Governance (2003)). As the OECD itself summarises, a host of papers have come to conclusions - based upon the indicators - that employment protection legislation harms growth, productivity, technology adoption, that it reduces investment, or may hamper job creation. Given that the evidential basis of the OECD Indicators cannot be regarded as credible, it follows that the conclusions of this body of research must be regarded as open to re-evaluation, and adjustment.

By contrast, to give just two examples, empirical research based upon the CBR Labour Regulation Index has found, first, that labour rights encourage higher levels of innovation. This followed from econometric work linking the number of patents filed in each jurisdiction to the quality of employment protection laws: VV Acharya and RP Baghai, 'Labor Laws and Innovation' (2013) 56(4) Journal of Law and Economics 997. Second, it has been found that employment protection laws (including collective agreements and participation rights) have a positive effect on employment, equality, and labour's share of income, and probably productivity: Z Adams, et al, 'The economic significance of laws relating to employment protection and different forms of employment: Analysis of a panel of 117 countries, 1990-2013' (2019) 158(1) International Labour Review 1, 17. It seems prudent to predict that empirical research will continue to produce the same results.

The central point is that we must defend the conduct of evidence-based, transparent, interdisciplinary research. It would be very unfortunate indeed if, between the CBR, the ILO, the OECD, or other indicators, empirical research continued to be conducted, with differing results, based upon different versions of legal and economic reality. On the contrary, it would be desirable to see a convergence of each set of indicators, through an informed, deliberative dialogue, resolution of differences based upon evidence, and a commitment to getting it right. I 
have no doubt, based upon the people I have met at this workshop, that this is precisely what the OECD is committed to today, and I am sure that the OECD, as one of the most important sources of data and research, is more than equal to such a task. 